\title{
PERENCANAAN GEDUNG ASRAMA PUTRI PONDOK PESANTREN TAHFIDZ QUR'AN (PPTQ) PARIT 24 TEMBILAHAN HILIR KECAMATAN TEMBILAHAN KABUPATEN INDRAGIRI HILIR"
}

\author{
Hana Zahra \\ Prodi Teknik Sipil, Fakultas Teknik dan Ilmu Komputer, Universitas Islam Indragiri, Tembilahan \\ Email: hanazahraz@gmail.com (korespondensi)
}

\begin{abstract}
The building is an important element in the development of an area. In the construction of a building must pay attention to matters relating to the conditions of the surrounding environment. For this reason, planning is necessary in accordance with the function of the building and the area to be built and must calculate how much material is needed. The planning of the female dormitory building is planned to fulfill the Indragiri Hilir district government program, namely 1 Village 1 Tahfidz House by following the Operational Technical Guidelines (PTO) of Maju Inhil Jaya Plus Integrated Village (DMIJPT) 2019 concerning Tahfidz Houses. The calculation of the structure of the dormitory uses the Cross method for calculating vertical loads and the Portal method for calculating horizontal loads
\end{abstract}

Keywords: Building, dormitory, Cross Method, Portal Method

\begin{abstract}
Abstrak
Gedung merupakan salah satu unsur penting dalam hal pengembangan suatu daerah. Dalam pembangunan sebuah gedung harus memperhatikan hal-hal yang berkaitan dengan kondisi lingkungan sekitar. Untuk itu perlu dilakukan perencanaan yang sesuai dengan fungsi gedung dan wilayah yang akan dibangun serta harus menghitung berapa besar kebutuhan material yang diperlukan. Perencanaan Gedung asrama putri ini direncanakan untuk memenuhi program pemerintah kabupaten Indragiri Hilir yaitu 1 Desa 1 Rumah Tahfidz dengan mengikuti Petunjuk Teknis Operasional (PTO) Desa Maju Inhil Jaya Plus Terintegritas (DMIJPT) Tahun 2019 tentang Rumah Tahfidz. Perhitungan struktur gedung asrama ini menggunakan metode Cross untuk perhitungan beban vertikal dan Metode Portal untuk perhitungan beban horizontal.
\end{abstract}

Kata kunci: Gedung, asrama, Metode Cross, Metode Portal

\section{PENDAhUlUAN}

Gedung merupakan salah satu unsur penting dalam hal pengembangan suatu daerah. Dalam pembangunan sebuah gedung harus memperhatikan hal-hal yang berkaitan dengan kondisi lingkungan sekitar. Untuk itu perlu dilakukan perencanaan yang sesuai dengan fungsi gedung dan wilayah yang akan dibangun serta harus menghitung berapa besar kebutuhan material yang diperlukan.

Perencanaan sebuah gedung harus dapat menjamin kekuatan serta fungsi gedung itu sendiri. Kekuatan gedung tersebut harus dapat memikul beban mati, beban hidup dan beban gempa yang terjadi di wilayah tersebut. Pada perencanaan gedung ini ditetapkan di wilayah gempa 1 . Seorang perencana harus menghitung dengan teliti agar nantinya Gedung tersebut dapat menahan beban-beban yang ada.
Dewasa ini, kajian terhadap tahfidz alQur'an dirasakan sangat signifikan untuk dikembangkan. Banyak lembaga pendidikan Islam di Indonesia saat ini yang menggalakkan dan mengembangkan program tahfidz Al-Qur'an. Hal ini menunjukkan antusiasme masyarakat muslim Indonesia yang tinggi untuk menghafal al-Qur'an dan menjadikan anak anak mereka sebagai penghafal al-Qur'an. Tren ini juga sebagai tanda akan kemajuan pendidikan Islam. Meskipun sebetulnya menghafal al-Qur'an bukanlah suatu hal yang baru bagi umat Islam, karena menghafal alQur'an sudah berjalan sejak lama di pesantren-pesantren.

Pesantren tahfidzul Qur'an merupakan salah satu bentuk lembaga keagamaan yang memiliki karakteristik dalam mengkhususkan pembelajarannya pada bidang tahfidzul Qur'an. Pesantren tahfidzul Quran 
menyediakan kurikulum pembelajaran yang menitik beratkan pada kegiatan menghafal al-Qur'an. Hal ini dilakukan agar santri dapat menghafal keseluruhan ayat-ayat al-Qur'an dengan baik dan benar, sekaligus mampu untuk menjaga hafalannya. Beratnya program tahfidz yang harus dihadapi oleh para santri, mewajibkan mereka harus mampu untuk menjaga konsentrasi dan penuh ketelatenan dalam mengahafal ayatayat al-qu'ran. (Lutfy, 2013:159)

Pentingnya bangunan penunjang sarana dan prasarana bagi para tahfidz qur'an sangat mempengaruhi efektivitas dan konsentrasi para tahfidz dalam menghafal qur'an. Salah satu bangunan penunjangnya adalah Gedung asrama.

Asrama adalah hunian bersama bagi pelajar yang dibangun dalam berbagai skala, mulai dari skala kecil (sampai 50 penghuni) hingga skala sangat besar dengan penyediaan lebih dari 200 kamar. Di berbagai negara, asrama ini telah dirancang dan dibangun dengan standar-standar khusus sesuai dengan jenjang pendidikan penghuninya.

Bangunan asrama menjadi area yang perlu mendapat perhatian karena telah ada panduan internasional diantaranya standar desain asrama dan kaitannya dengan perilaku penghuni, dan standar spesial asrama dalam buku-buku standar ruang, antara lain Times Saver Standard dan Architect's Data. Kajian terhadap kaitan antara desain ruang dan fasilitas asrama dengan perilaku penghuni perlu dilakukan untuk mengetahui tingkat keterkaitan antara desain dan perilaku agar nantinya dapat dilakukan kajian untuk menyusun panduan desain yang sesuai dengan kebutuhan dan karakter penghuni secara umum.

\section{TINJAUAN PUSTAKA}

\subsection{Kriteria Perencanaan}

Kriteria perencanaan asrama pondok pesantren berdasarkan standar dari NAD (Neufert Architecture Data) dan Time Saver Standards for Building Type.

\subsection{Pembebanan}

Beban-beban pada struktur bangunan bertingkat, menurut arah bekerjanya dapat dibagi menjadi dua, yaitu : (PPI, 1983)

1. Beban Vertikal (Gravitasi).

a. Beban Mati (Dead Load).

b. Beban Hidup (Live Load).

c. Beban Air Hujan.

2. Beban Horizontal (Lateral).

a. Beban Gempa (Earthquake Load).
b. Beban Angin (Wind Load).
c. Tekanan Tanah dan Air Tanah.

\subsection{Struktur Beton Bertulang}

Struktur merupakan satuan dari salah satu ataupun beberapa material yang memiliki kekuatan menahan ataupun menopang suatu beban, baik beban mati atapun beratnya sendiri, beban hidup, beban gempa, beban angin, dan beban khusus lainya.

Beton adalah campuran antara semen portland atau semen hidraulik yang lain, agregat halus, agregat kasar dan air, dengan atau tanpa bahan tambahan yang membentuk masa padat (SNI 03- 2847 2002, Pasal 3.12).

Beton bertulang adalah beton yang ditulangi dengan luas dan jumlah tulangan yang tidak kurang dari nilai minimum yang di syaratkan dengan atau tanpa prategang, dan direncanakan berdasarkan asumsi bahwa kedua bahan tersebut bekerja sama dalam memikul gaya-gaya (SNI 03- 2847 - 2002, Pasal 3.13).

\subsection{Perencanaan Struktur Atas (Upper Structure)}

Perencanaan Atas terdiri dari struktur atap dan portal. Struktur portal merupakan satu kesatuan antara balok, kolom dan pelat lantai. Perencanaan struktur portal dilakukan berdasarkan Peraturan Beton Bertulang Indonesia (PBI) 1971, Standar Negara Indonesia (SNI) 03-2847-2002, dan peraturan yang terbaru yakni Standar Negara Indonesia (SNI) 2847-2013.

Seluruh prosedur perhitungan mekanika/analisa struktur untuk struktur atas dilakukan dengan Metode Cross untuk perhitungan beban vertikal dan Metode Portal untuk perhitungan beban horizontal. Dengan dua metode ini akan didapatkan gaya - gaya dalam yang bekerja pada struktur.

\subsection{Perencanaan Struktur Bawah (Sub Structure)}

Struktur bawah (sub structure) yang berupa pondasi, merupakan struktur yang berfungsi untuk meneruskan beban-beban dari struktur atas ke dalam lapisan tanah. Dalam menentukan jenis pondasi yang sesuai kita perlu mempertimbangkan beberapa hal sebagai berikut :

1. Keadaan tanah, seperti parameter tanah, daya dukung tanah, dll

2. Jenis struktur atas (fungsi bangunan)

3. Anggaran biaya yang dibutuhkan

4. Waktu pelaksanaan yang direncanakan 


\subsection{Metode Cross dan Metode Portal}

Metode Cross atau biasa disebut metode distribusi momen pertama kali diperkenalkan oleh Harry Cross pada tahun 1933 dalam bukunya yang berjudul "Analysis of Continous Frames by Distributing Fixed-End Moments". Metode ini merupakan salah satu metode yang dipakai untuk analisis struktur balok menerus dan portal statis tak tentu.

Metode portal adalah metode dimana semua gaya lintang di dalam balok dari tingkat yang sama. Terdapat gaya aksial tarik dan tekan yang sama besarnya pada kolom luar, tapi tidak ada gaya aksial didalam kolom-kolom dalam.

\subsection{Dilatasi}

Dilatasi adalah sebuah sambungan / garis pada sebuah bangunan yang dikarenakan sesuatu hal memiliki sistem struktur berbeda. Dilatasi digunakan pada pertemuan antara bangunan yang rendah dengan yang tinggi, antara bangunan induk dengan bangunan sayap, dan bagian bangunan lain yang mempunyai kelemahan geometris.

\subsection{Rencana Anggaran Biaya (RAB)}

Rencana anggaran biaya adalah rencana anggaran biaya suatu bangunan atau proyek adalah perhitungan banyaknya biaya yang diperlukan untuk bahan dan upah, serta biaya-biaya lain yang berhubungan dengan pelaksanaan bangunan atau proyek tersebut ( Bachtiar Ibrahim 1993 ).

Rencana anggaran biaya merupakan perkiraan biaya yang diperlukan untuk setiap pekerjaan dalam suatu proyek konstruksi sehingga akan diperoleh biaya total yang diperlukan untuk suatu proyek (Sugeng Djojowirono 1984 ).

\section{METODOLOGI PENELITIAN}

Metodologi penelitian yang digunakan adalah studi pustaka. Dalam Tugas Akhir ini dibutuhkan tahapan pengerjaan yang teratur dan sistematis agar mendapatkan hasil yang sesuai dengan harapan di akhir penyusunan. Selain tahapan pengerjaan juga dijelaskan mengenai rencana kerja. Diagram alir penelitian dan rencana kerja (flowchart) dapat dilihat dibawah ini.

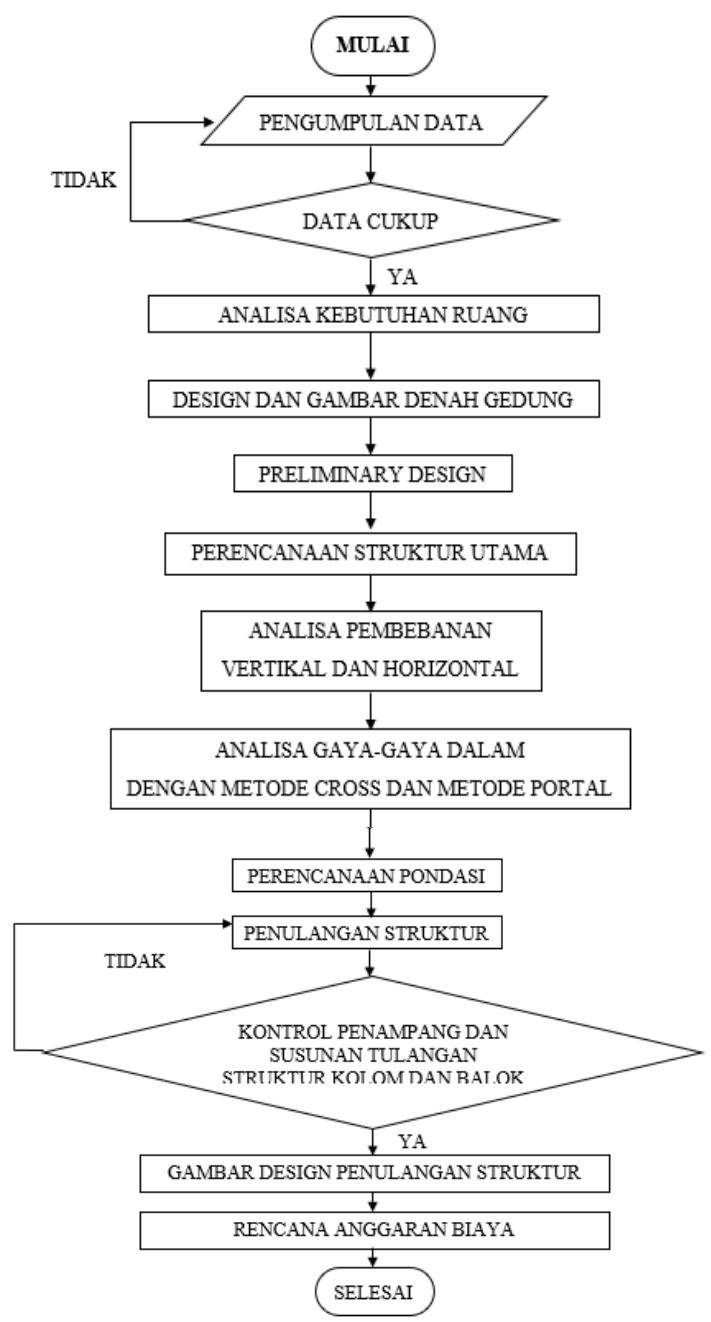

Gambar 1. Flowchart Analisis dan Perencanaan Gedung "Studi Kasus Perencanaan Gedung Asrama Putri Pondok Pesantren Tahfidz Qur'an (PPTQ) Parit 24 Tembilahan Hilir Kecamatan Tembilahan Kabupaten Indragiri Hilir

\section{HASIL DAN PEMBAHASAN}

\subsection{Kebutuhan Ruang}

Kebutuhan ruangan pada Gedung Asrama Putri Pondok Pesantren Tahfidz Qur'an (PPTQ) Parit 24 Tembilahan Hilir berdasarkan dengan Data arsitek (DA), Time Saver Standard (TSS), dan Asumsi (AS).

Time Saver Standards for Building Types menyebutkan bahwa luas ruangan minimum untuk satu kamar dengan 2 tempat tidur tingkat yang dihuni 4 orang adalah 65 kaki persegi atau kurang lebih 6 meter persegi.

Asrama putri memiliki fasilitas kamar, toilet, area cuci dan jemur, serta area komunal. Setiap kamar asrama di huni oleh 8 orang santri sehingga dapat dijelaskan dalam bentuk tabel berikut : 
Tabel 1. Analisa Rencana Kebutuhan Ruang

\begin{tabular}{|c|c|c|c|c|c|c|c|}
\hline \multirow[b]{2}{*}{ No } & \multirow[b]{2}{*}{ SARANA } & \multirow{2}{*}{\begin{tabular}{c|} 
LUAS \\
STANDA \\
$\mathbf{R}\left(\mathrm{MM}^{*}\right)$ \\
\end{tabular}} & \multicolumn{4}{|c|}{ RENCANA } & \multirow[b]{2}{*}{ KETERANGAN } \\
\hline & & & \begin{tabular}{|l|} 
PJG \\
(M)
\end{tabular} & \begin{tabular}{|l} 
LBR \\
$(\mathbb{M})$
\end{tabular} & $\begin{array}{l}\text { LUAS } \\
(\mathrm{MF})\end{array}$ & $\mathrm{ML}$ & \\
\hline 1 & \multicolumn{7}{|c|}{ Ruang Gedung Asrama Putri } \\
\hline \multirow[t]{6}{*}{ A. } & Ruang Umum & & & & & & \\
\hline & Ruang Komunal & 40 & 6 & 8 & 48 & 1 & \\
\hline & Lobby & 30 & 6 & 8 & 48 & 1 & \\
\hline & Dapur & 20 & 6 & 8 & 48 & 1 & \\
\hline & Selasar & 4 & 42 & 2 & 84 & 3 & \\
\hline & Teras dan Balkon & 4 & 42 & 1 & 42 & 3 & \\
\hline B. & Ruang Tidur & & & & & & \multirow{5}{*}{$\begin{array}{l}\text { Rasio } \\
\text { minimum luas } \\
\text { ruang tidur } \\
\text { adalah } 2 \mathrm{~m}^{2} \\
\text { peserta didik }\end{array}$} \\
\hline & Ruang Tidur Santri & 12 & 6 & 8 & 48 & 16 & \\
\hline & Ruang Tidur Ustadzah & 6 & 6 & 8 & 48 & 5 & \\
\hline \multirow[t]{3}{*}{ C. } & Ruang Makan & & & & & & \\
\hline & Ruang Makan Santri & 24 & 24 & 8 & 192 & 1 & \\
\hline & Ruang Makan Ustadzah & 24 & 6 & 8 & 48 & 1 & \\
\hline \multirow[t]{3}{*}{ D. } & $\begin{array}{l}\text { Kamar Mandi dan R. } \\
\text { Cuci }\end{array}$ & & & & & & \\
\hline & $\begin{array}{l}\text { Kamar Mandi dan R. } \\
\text { Cuci }\end{array}$ & 2.9 & 3 & 1.6 & 4.8 & 20 & \\
\hline & Kamar Mandi dan Wc & 2.9 & 3 & 2 & 6 & 6 & \\
\hline \multirow[t]{2}{*}{ E. } & Area Jemuran & & & & & & \\
\hline & Area Jemuran & 3 & 6 & 8 & 48 & 2 & \\
\hline \multirow[t]{6}{*}{ F. } & Ruang Penunjang & & & & & & \\
\hline & Ruang Belajar & 1 & 6 & 8 & 48 & 4 & \\
\hline & Ruang Sterilisasi Lt. 1 & 2 & 3 & 4 & 12 & 1 & \\
\hline & Ruang Sterilisasi & 2 & 3 & 8 & 24 & 2 & \\
\hline & Gudang & 10 & 3 & 3.8 & 11.4 & 3 & \\
\hline & & \multicolumn{4}{|c|}{ Total Ruang } & 70 & \\
\hline
\end{tabular}

(Sumber: Data Olahan, 2020)

\subsection{Preliminary Design}

Preliminary design berupa pendekatan perencanaan dengan asumsi yang disesuaikan dengan peraturan yang berlaku pada Standar Nasional Indonesia (SNI 03 - 2847 - 2002) yaitu Tata Cara Perhitungan Struktur Beton Untuk Bangunan Gedung dan SKSNI T-15-1991-03.

Analisa portal menggunakan Metode Cross, sedangkan untuk penulangan menggunakan peraturan Standar Nasional Indonesia (SNI 03 2847 - 2002) yaitu Tata Cara Perhitungan Struktur Beton Untuk Bangunan Gedung dan SKSNI T-15-1991-03.

\subsection{Analisa Pembebanan}

Analisa pembebanan dilakukan berdasarkan Standar Nasional Indonesia untuk gedung berlantai banyak/gedung bertingkat. Analisa pembebanan akibat beban vertikal dan beban horizontal ditinjau dari denah rencana gedung yang terdiri dari 3 lantai, area pembebanan dapat dilihat dari gambar denah dibawah ini :

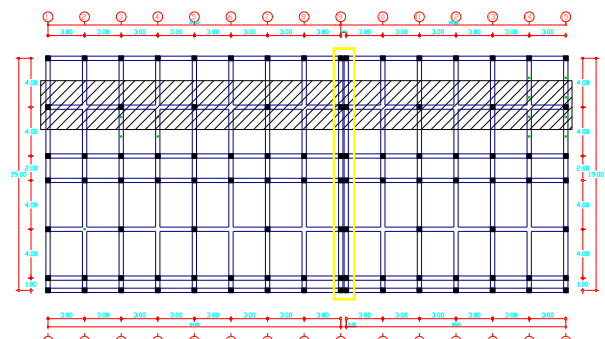

Gambar 2. Denah Pembebanan

\subsection{Analisa Struktur}

Analisa gaya-gaya dalam pada struktur portal yang dianalisa akibat pembebanan menggunakan Metode Cross untuk perhitungan beban vertikal dan Metode Portal untuk perhitungan beban horizontal.

\subsection{Perencanaan Pondasi}

Pondasi yang dipakai pada perencanaan Gedung ini menggunakan pondasi tiang pancang (Mini Pile). Hal ini berdasarkan dari data tanah yang didapat dengan menggunakan alat sondir. Sondir yang diperhitungkan pada desain pondasi ini pada kedalaman $18 \mathrm{~m}$ dengan nilai (qc) $\geq 110$ $\mathrm{kg} / \mathrm{cm} 2$. Tiang pancang yang digunakan adalah panjang 6 meter, maka yang digunakan dalam perencanaan ini adalah pada kedalaman 18 meter.

\subsection{Penulangan Struktur}

Penulangan struktur pada design gedung asrama ini, terdiri dari :

1. Penulangan struktur pelat lantai.

2. Penulangan struktur kolom.

3. Penulangan struktur balok.

\subsection{Rencana Anggaran Biaya}

Rencana anggaran biaya (RAB) adalah tolak ukur dalam perencanaan pembangunan, baik rumah tinggal, ruko, rukan maupun gedung lainya. Dengan RAB kita dapat mengukur kemampuan materi dan mengetahui jenis-jenis material dalam pembangunan, sehingga biaya yang kita keluarkan lebih terarah dan sesuai dengan yang telah direncanakan.

\section{KESIMPULAN}

Berdasarkan Perencanaan Gedung Asrama Putri Pondok Pesantren Tahfidz Al-Qu'ran (PPTQ) Bertingkat Tiga Parit 24 Tembilahan Hilir Kecamatan Tembilahan Kabupaten Indragiri Hilir dapat disimpulkan yaitu :

1. Kebutuhan Ruangan yang diperlukan adalah dengan total ruang berjumlah 70 ruang yang terdiri dari kamar tidur santriwati, kamar tidur ustadzah, kamar mandi ustadzah dan santriwati, ruang belajar, ruang jemur, ruang makan, dapur, ruang sterilisasi dan gudang.

2. Struktur yang ditinjau pada Perencanaan Gedung Asrama Putri Pondok Pesantren Tahfidz Al-Qu'ran (PPTQ) Bertingkat Tiga Parit 24 Tembilahan Hilir Kecamatan Tembilahan Kabupaten Indragiri Hilir adalah struktur dengan pendekatan pemodelan struktur dengan Metode Cross dan Metode Portal. 
3. Hasil dimensi serta penulangan yang direncanakan berdasarkan tinjauan analisa perhitungan struktur kolom dan balok pada portal As. B - B adalah sebagai berikut :

a. Dimensi kolom yang direncanakan 40 $x 40 \mathrm{~cm}$

b. Dimensi balok sloof yang direncanakan $40 \times 40 \mathrm{~cm}$

c. Dimensi balok yang direncanakan $35 \mathrm{x}$ $50 \mathrm{~cm}$

4. Perencanaan struktur gedung bertingkat menggunakan bahan material beton bertulang

5. Gaya-gaya dalam yang terjadi pada struktur dihitung menggunakan Metode Cross dan Metode Portal.

6. Hasil perhitungan rencana anggaran biaya perencanaan gedung adalah Rp. 9,950,510,000.00 (Sembilan Milyar Sembilan Ratus Lima Puluh Juta Lima Ratus Sepuluh Ribu Rupiah)

\section{DAFTAR PUSTAKA}

[1] Mulyadi, Meli. " Asrama Mahasiswa Universitas Tanjungpura". Jurnal online mahasiswa Arsitektur, Universitas Tanjungpura Vol.6 No.1, 2018, Hal 4

[2] Wulandari. Ratri, "Analisa Kaitan Desain Asrama Dengan Perilaku Penghuni Melalui Studi Analisa Konten Penelitian Sejenis". Jurnal I D E A L O G, Ide Dan Dialog Indonesia Vol. 1 No. 3, 2016, Hal 4.

[3] Angreni, Ida Ayu Ari. "Perhitungan Rencana Anggaran Biaya Bangunan Gedung Dengan Perbandingan Harga Satuan Kontraktor". Jurnal Ilmiah Desain Dan Kontruksi Vol 10, No.01. 2011. Hal 1.

[4] Angreni, Ida Ayu Ari. "Perhitungan Rencana Anggaran Biaya Bangunan Gedung Dengan Perbandingan Harga Satuan Kontraktor". Jurnal Ilmiah Desain Dan Kontruksi Vol 10, No.01. 2011. Hal 1.

[5] A.Soedjarajat Sastraatmaja, 1984. Analisa Anggaran Biaya Pelaksanaan, Penerbit Nova Bandung.

[6] Adiyono, 2006, Menghitung Konstruksi Beton, Penebar Swadaya, Jakarta, 2006.

[7] Frick, Heinz, Ir. 1978, Mekanika Teknik 1 \& 2, Kanisius, Yogyakarta, 2007

[8] Karlen, Mark, Dasar-dasar Perencanaan Ruang, Edisi Kedua, Erlangga, 2007

[9] L. Taulu, Ir, dkk, Mekanika Tanah dan Teknik Pondasi, Pradnya Paramita, Jakarta, 1981

[10] Sunggono kh. Ir, 1995, Buku Teknik Sipil, Nova Bandung. 